\title{
Real Time Water Monitoring System using IoT
}

\author{
Schindhya.R ${ }^{1}$, Simi V.P ${ }^{2}$, Sathya.E ${ }^{3}$, Janani.B ${ }^{4}$ \\ Student,Computer Science and Engineering, Adithya Institute of Technology ${ }^{1,2,3}$ \\ Assistant Professor, Computer Science and Engineering, Adithya Institute of Technology ${ }^{4}$
}

\begin{abstract}
Water is the prime necessity of every living being in the world. Being the most depleted and most polluted indispensable resource, we are in dire need of saving every possible drop of water. Over two thirds of earth's surface is covered by water and others are taken by land. As Earth's population continues to grow, people are putting everincreasing pressure on the planet's water resources. Population, household size, and growth and affluence all affect how much water is used. Factors such as climate change have increased pressures on natural water resources especially in manufacturing and agricultural irrigation. In a sense, our oceans, rivers, and other inland waters are being squeezed by human activities not so they take up less room, but so their quality is reduced. Poorer water quality means water pollution. The usage of water being the same, cannot be reduced beyond a certain extent. Hence, to preserve the water that is remaining, the quality of the water is to be monitored. The water quality can be decided using different parameters like $\mathrm{pH}$,temperature and Dissolved Oxygen[DO] which are recommended to be measured for determining the quality of water. Wireless Sensor Technology is been used in IoT Environment using Arduino technology. The system's measurement capacity ranges from $0^{\circ} \mathrm{C}$ to $80^{\circ} \mathrm{C}$ for water temperature; from 0 to $14 \mathrm{on} \mathrm{pH}$ scale. The main goal of this application is that, it ensures to be an effective way for real time water quality monitoring at the lowest cost possible
\end{abstract}

Keywords: IoT, WSN, Dissolved Oxygen[DO], pH

\section{INTRODUCTION}

The Internet of Things (IoT) is a inter-networking of turn it into an output - activating a motor, turning on an physical devices of interconnected objects which are LED, publishing a message online, etc. The board should outfitted with sensors, actuators etc. These devices are be instructed on what to do by sending a set of instructions uniquely addressable and use standard communication to the micro controller on the board. To do so, the Arduino protocols in a networking environment including objects programming language (based on Wiring) and the Arduino of totally different functionality, technology and Software (IDE) based on processing are made. Arduino is application fields. The physical objects that are being preferred because of its simple and clear programming connected will possess with more sensors. Each sensor environment, cross- platform convenience and its cost will monitor a specific condition such as $\mathrm{pH}$ and efficiency.

temperature. In IoT, these sensors will connect to each other and to systems that can understand or present information from which the data feeds. These sensors will provide new information to people.

While, the world water monitoring day is celebrated on September 18, this monitoring can help with water pollution detection and contamination of water. The quality of water can be checked using temperature, Dissolved Oxygen(DO) and $\mathrm{pH}$ which are the typical parameters collected by quality monitoring systems. The traditional methods of water quality monitoring involve the manual collection of water samples from different locations. These water samples were tested in the laboratory using analytical technologies. Such an approach is time consuming and is considered to be inefficient. Hence constructing an even more efficient monitoring system based on the WSNs (Wireless Sensor Networks) would present us with advantages such as low cost and a collection of a variety of parameters.

Arduino is an open source and user community that designs electronics platform based on hardware and software. Arduino boards are able to read inputs - light on a sensor, a finger on a button, or a Twitter message - and

This monitoring is quintessential for human beings because, there are a number of diseases which are being caused due to the polluted drinking water which can be prevented using the water monitoring system. A prototype is being proposed to monitor water quality in IoT environment.

\section{ARDUINO BOARD \\ The The Arduino Uno is a micro controller board. And it is based on the ATmega328. UNO has 14 digital input/output pins (of which 6 can be used as PWM outputs), 6 analog inputs, a ceramic resonator of $16 \mathrm{MHz}$, a USB connection, an ICSP header, a reset button and a power jack,. This also contains everything needed to support the micro controller; and simply connect it to a computer with a USB cable or power it with a AC-to-DC} adapter or battery

The Uno differs from all preceding boards in that it does not use the FTDI USB-to-serial driver chip. Instead, it features the Atmega16U2 (Atmega8U2 up to version R2), which is programmed as a USB-to-serial converter. Revision 2 of the Uno board has a resistor pulling the $8 \mathrm{U} 2$ 
HWB line to ground, making it easier to put into DFU mode.

The Arduino Uno can be programmed with the Arduino Software (IDE)).

\section{TANK}

A container is used to store the water and it is termed as water tank, to provide storage of water for use in many applications like drinking water, irrigation, for plants and livestock as well as many other uses. The place where the water from the dam is being stored to supply for various places before which the purification is being made. The water with large quantity i.e. about one crore liters of water is being stored here. Even during the absence of electricity, water can be supplied for nearly an hour. The water from the tank is separated into several parts and being stored. The storage tanks are separated in order to convert the hard water into soft water which will be useful for drinking purposes. Here, the basic sedimentation process occurs which removes the heavy particles.

\section{DISINFECTION}

In a chamber called Chlorine house, the very first step of adding chlorine gas into water throughout the day is done. In case of excessive contamination of impurities, the second step involves the addition of a chemical salt called Alum(AlSO4) to the contaminated water in order to remove the impurities. The dividing chamber divides this water into major parts for the next stage of purification process. Basically this stage consists of two processes namely, Pre-chlorination and Post-chlorination. The prechlorination stage involves the Spling chamber where the bacteria from the raw water are killed. This will also minimize the growth of algae. The liquid chlorine is added to water after the destruction of bacteria and algae.

The $\mathrm{pH}$ value of water is being maintained at this spot. In the post-chlorination phase, about $0.1 \mathrm{ppm}$ of chemicals involved in the purification process is maintained. Then, the Clariflocculator separates the sludge from the water. This contains a flash mixer which pushes the sludge into the pipes. The water flows through the stand well.

\section{FILTERATION}

The water from the clariflocculator flows through the stand well and reaches the filter bed. There are a number of filter beds that use rapid sand filtration technique. The fine particles from water are being deposited over here by the traditional filter bed method. In this process, an air compressor is used for purifying the mud where the filtered water is added to clean the bed. Not all the filter beds are used at the same time, but each filter bed is given its turn and is operated one by one in no particular order.

\section{PUMPING AND DISTRIBUTION}

Finally the water filtered and stored will be pumped out and distributed to various places of the town.
BLOCK DIAGRAM OF THE WATER PLANT:

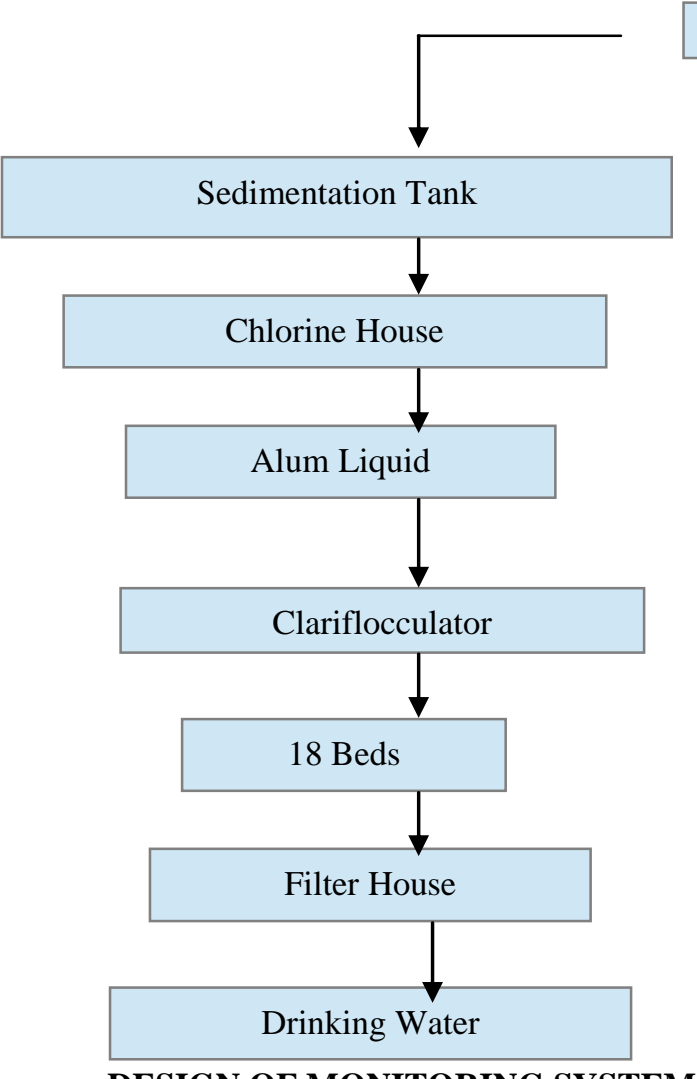

DESIGN OF MONITORING SYSTEM:

\section{BLOCK DIAGRAM :}

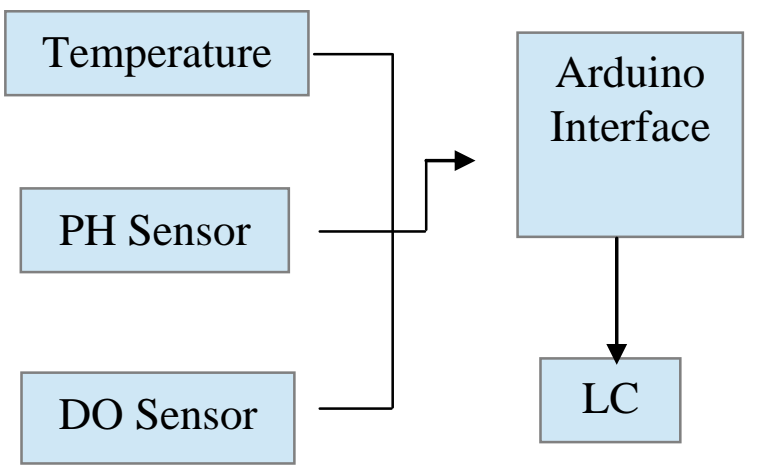

Impurities sensing system manages a Wireless Sensor Network (WSN) that helps to monitor the quality of water with the help of information sensed by the sensors immersed in water. The parameters such as $\mathrm{pH}$,amount of dissolved oxygen,temperature, etc. Are been monitored.

A WSN featuring a high power transmission Arduino based technology because of the simplicity of its deployment, low cost, minimal power consumption, reliability and high scalability. There a Display should be able to display the parameters being monitored continuously in real time. The Sensor will also check the water quality by using these parameters involved in the 
water quality monitoring measured in real time by the sensors that send the data to the monitoring room.

The $\mathrm{pH}$ stands for "Potential of Hydrogen," referring to the amount of hydrogen found in a substance (in water).Every aqueous solution can be measured to determine its $\mathrm{pH}$ value. This value normally ranges from 0 to $14 \mathrm{pH}$. Values below $7 \mathrm{pH}$ exhibit acidic properties. Values above $7 \mathrm{pH}$ exhibit basic (also known as caustic or alkaline) properties. Since $7 \mathrm{pH}$ is the center of the measurement scale. Most living things depend on a proper $\mathrm{pH}$ level to sustain life.

All human beings and animals depend on internal mechanisms to maintain the $\mathrm{pH}$ level of their blood. The blood flowing through our veins may have a range of $\mathrm{pH}$ between 7.35 and 7.45. Exceeding this range by as little as one- tenth of a $\mathrm{pH}$ unit could prove fatal. Rainwater is naturally acidic (below $7.0 \mathrm{pH}$ ). Rain is typically round $5.6 \mathrm{pH}$ but, in some areas, it increases to harmful levels between 4.0 and $5.0 \mathrm{pH}$ due to atmospheric pollutants.

Temperature is an important factor to assessing water quality. In addition to its own effects, temperature influences several other parameters and can alter the physical and chemical properties of water.

Dissolved oxygen refers to the level of free, noncompound oxygen present in water or other liquids. It is an important parameter in assessing water quality because of its influence on the organisms living within a body of water.

Arduino can sense the environment by receiving input from different sensors. The board with the Microcontroller, using arduino programming language based on wiring and arduino development based on programming processing. The Arduino Integrated Development Environment is a cross platform application and derived from the IDE for the processing programming language and wiring projects.

With the system, The sensor data is Written to the serial port using serial-lib and a small processing program is also written so that reads the data from the serial port and writes it to a file Or else it can be displayed and where it can be monitored based on the sensor values the quality can be monitored. An Alarm can also be used when the properties of the normal water changes out.

\section{CONCLUSION}

Water quality is a measure of the condition of water relative to the requirements of biotic species and or to any human need or purpose. It is most frequently used by reference to a set of standards against which compliance can be assessed. The most common standards used to assess water quality relate to health of ecosystems, safety of human contact, and drinking water. Implying these methodologies we can say that the proposed system is more suitable to monitor water quality parameters in real time. The proposed system introduces wireless sensor networking using several sensors to measure water quality, where micro controllers make sensor network simple at reduced cost and its functionality is proven to be more efficient. Two different ways to monitor water such as water quality monitoring. Without quality water, there are a number of issues that effect the living beings. Therefore, it becomes mandatory to monitor the quality of water and ensure that the quality is being maintained at the desirable range, without which there would be serious consequences in the lifestyle of every living being.

\section{REFERENCES}

[1]Iot Based Water Quality Monitoring System , JAYTI BHATT, JIGNESH PATOLIYA,49th IRF International Conference, 21st February 2016, Pune, India.

[2]Smart Device to monitor water quality to avoid pollution in IoT environment. Pandian D R, Dr. Mala K, International Journal of Emerging Technology in Computer Science \& Electronics (IJETCSE) Volume 12 Issue 2 -JANUARY 2015.

[3]IEEE 802.15.4 Based Water Quality Monitoring System,Nirav M Parmar, Rahul S Goradia,IJARIIE-Vol-1 Issue-2 2015.

[4]Real Time Water Quality Monitoring System, Mithila Barabde, Shruti Danve, International Journal of Innovative Research in Computer and Communication Engineering (An ISO 3297: 2007 Certified Organization), Vol. 3, Issue 6, June 2015

[5]Smart Water Monitoring System Using Wireless Sensor Network at Home/Office,Ms T.Deepiga, Ms A.Sivasankari, International Research Journal of Engineering and Technology (IRJET) Volume: 02 Issue: 04July-2015. 